\title{
Bird Strike Virtual Testing for Preliminary Airframe Design
}

\begin{abstract}
Purpose - To employ numerical methods early in the airframe design process and access the structural performance of wing leading edge devices made of different materials and design details, under bird strike events

Design/methodology/approach - To numerically model bird strike events using explicit finite element analysis

Findings - To draw structural performance charts related to materials and general design details, in order to explore the design space dictated by the current applicable airworthiness requirements

Practical implications - The paper makes use of the current capability in the numerical tools available for structural simulations and exposes the existing limitations in the terms of material modelling, material properties and fracture simulation using continuum damage mechanics. Such results will always be in the need of fine-tuning with experimental testing, yet the tools can shed some light very early in the design process in a relative inexpensive manner, especially for design details down selection like materials to use, structural thicknesses and even design arrangements.

Originality/value - Bird strike simulations have been successfully employed on aircraft design, mainly at the manufactured articles design validation, testing and certification. The article presents a hypothetical early design case study of leading edge devices for appropriate material and skin thickness down selection
\end{abstract}

Keywords Bird Strike, Fiber Metal Laminate, Aircraft Design, Explicit Finite Element Analysis, Smoothed Particle Hydrodynamics

Paper type Case study 


\section{Abstract}

External airframe structural components facing the aircraft flight direction are prone to bird collisions. Aircraft manufacturers meet the bird strike airworthiness requirements through physical bird strike testing. Mainly due to the high costs involved in the certification process, recent studies have highlighted the capabilities and benefits of hybrid simulation-experiment techniques that reduce certification costs. The numerical investigation presented herein, studied the bird-strike simulation methodologies implemented to support airframe manufacturers to partially fulfil the current certification airworthiness requirements. The methodology can be also applied during preliminary aircraft parametric design stages. In the current study, the method was applied onto an aircraft wing leading-edge preliminary design, which led to design exploration by correlating the leading-edge skin materials and thicknesses with the rib pitch positioning. The bird-strike impact model was simulated using the Smoothed Particle Hydrodynamics numerical method using ABAQUS® Explicit finite element package. The materials benchmarked were aluminium alloy 2024-T3, carbon fibre reinforced epoxy IM7/8552 and S2 glass Fibre Metal Laminate GLARE $®$. The design goal of the case study was to provide with preliminary evidence for impact resistance, quantified as residual permanent structural deformation of the critical structural components for which design charts were drawn and presented herein.

\section{Introduction}

Bird impact accidents have been considered a threat to flight safety since the start of aviation. Large costs for airline operators are associated with bird strike accidents with potential and most often damaged components being jet engines, windshields, wing and tail structures, landing gear and nose radomes. The direct and indirect airline costs due to bird strike can be divided into the ones concerning aircraft repair and replacement costs, fuel used and dumped during emergency landing procedures, as well as passenger compensation. Since 1912, more than 50 aircraft have been lost, while annual costs for airline operators are estimated to reach over 1 billion dollars (MacKinnon 2004).

Aviation authorities across the globe have implemented airworthiness requirements, which require the aircraft to be certified for safe continue flight and landing, having undergone bird strike events. An example of such certification requirements can be found in Certification Specification 25 for large transport aircraft, issued by EASA. Traditionally, OEMs conduct certification tests using real birds, typically dead or sedated chickens. These tests are cost-ineffective and they introduce large output data deviations between them, as real birds tend to differ greatly on their physical properties depending on the species. Furthermore, the airworthiness requirements solely define the bird's mass, without specifying restrictions in the bird's morphological properties, resulting in large data scatter between individual tests (Heimbs 2011). Due to the drawbacks related to bird strike testing using real birds, numerical modelling approaches have gained public acceptance defining it a popular research topic. 
Since the design and certification of the Airbus A340 aircraft, lightweight composite materials have been heavily implemented in airframe structures. Metals have been the dominant choice for aircraft applications well before composite materials, which resulted in more extensive research being conducted on impact behaviour. A proposed combination of metal and composite material into sandwich panels for aircraft applications was first introduced by Prof Boud Vogelesang at TU Delft University (Alderliesten 2017). Since its invention, FML technology has been applied in multiple aircraft structural components, including fuselage sections of the A380 wide-body airliner. FMLs are well known for their enhanced metal fatigue and impact characteristics and therefore this material technology finds perfect application on structural components prone to bird strikes.

In this paper, the impact behaviour of three material categories has been numerically studied in a wing LE, namely aluminium, carbon fibre reinforced composite and GLARE FML technology. Also, different internal structural design configurations have been investigated parametrically, by altering the skin support rib spacing relative to the choice of skin material and thickness.

\section{Bird Strike Numerical Modelling}

Bird strike events have been heavily researched and many related studies are available in the public domain. A vast variety of simulation models, many of which have been correlated with experimental results, have studied birds impacts on various types of aircraft components, in an effort to generate validated methodologies for bird strike modelling.

In the review study from Heimbs (2011), bird material modelling using bird substitutes was presented, where it was claimed that some of the main drawbacks of using actual birds are non-ethical, of poor hygiene and of ineffective results. It was reported that several bird material substitutes have been tested in the past, the conclusion being that the material that produced loading profiles similar to those of actual birds was gelatine. It was also mentioned that it is common practice for researchers to validate and calibrate the material properties of the projectile by comparing the simulation results with actual test data found in literature. The majority of experimental data used in bird strike studies were obtained from Wilbeck (1978) and Barber et al. (1978), results which were of low quality in some cases.

In terms of modelling techniques, Heimbs (2011) concluded that the three most applicable ones are classic finite element analyses using Lagrangian mechanics, the ALE and SPH methods. It has been claimed that the best discretization method for a bird strike event depends heavily on the specific application, parameter setup and even the software package employed. The lack of homogeneity in terms of modelling acceptance has been the main reason for none of these methods to be established as a standard numerical modelling technique.

Georgiadis et al. (2008) conducted a study on Boeing 787 movable TE flap made of composite materials. The study was an attempt to propose a validated simulation methodology that would prove the impact resistance of the TE flap, as well 
as providing a certification approach using numerical simulations. Experimental bird strike testing was conducted and compared against numerical analyses, where SPH was used for bird modelling. The simulation results reported the excellent agreement with the experimental data, with almost identical structural damage. The loads generated by simulation were in reasonably good agreement with the experiment, on occasions slightly higher on the simulation side. This study has managed to develop a certification compliance approach, capable of dramatically reducing the amount of impact tests required. According to the authors, this methodology improved design efficiency and safety through accurate and cheaper damage prediction methods.

McCarthy et al. (2004) conducted a bird strike impact study on a wing LE, where FML material was used for the structure. Numerical FE modelling was performed with the bird being modelled using the SPH method. Experimental work was also carried aiming to compare the response of real birds and substitute birds made of gelatine. The simulation results were compared with experimental data and an excellent agreement of the two was obtained. In general, the structural deformation was well predicted, although the folding pattern and the magnitude of deformation were somewhat different whilst the magnitude of the peak forces were found higher in the numerical model than in the experimental testing.

An industry sponsored study (Tho et al. 2008) involved the development of a novel numerical simulation methodology using the ALE and SPH methods for birds impacting on a tiltrotor flight vehicle cockpit nose, wing leading-edge and empennage. A slightly different approach was followed in the afore mentioned study, regarding the SPH bird modelling, in which a deactivation zone was added to release the bird particles that were no longer interacting with the impacted structure. That feature reduced the computational time and cost of the analysis. It was found that the ALE approach correlated reasonably well with experimental results of Wilbeck (1978), while the SPH method tended to overestimate the steady-state pressure. It was found in the analysis that both ALE and SPH triggered similar structural responses, while the bird deflection and splitting were equally similar. The study provided industry with confidence for using numerical methods for bird strike flight vehicle certification.

Another study from Heimbs (2011), focused on the numerical modelling of high-velocity impact of soft body projectiles on composite material structures. An interesting approach was followed in this study concerning the pre-loading of the plates before the impact occurred, based on the assumption that aircraft components are loaded in-flight. A $32 \mathrm{~g}$ gelatine bird was modelled for the strike upon a leading-edge flap, using CEL numerical method. The impactor was modelled as an Eulerian part with water-like properties. The simulation results were in good agreement with the experimental results, in terms of rib deformation and skin penetration.

An innovative study from a material technology perspective came from Kermanidis et al. (2005). The authors proposed a novel design for a tail-plane LE structure made of CFRP materials, capable of absorbing the kinetic energy carried by the bird. The skin's composite layered design employed an energy absorbing middle laminate made of Dyneema fibres, 
capable of elongating during impact and holding the projectile by tensile/membrane action. The failure pattern of the LE, as well as the maximum skin deformation obtained from simulation modelling and experimental testing were in agreement. The substitute bird gelatine model was realistic, with the bird's mass and density being set at $1.81 \mathrm{~kg}$, $950 \mathrm{~kg} / \mathrm{m} 3$ respectively. The modelling technique implemented for the bird was the SPH. It was found that the simulation and bird modelling predicted well the experimental observations, regarding the LE skin deformation and the bird's penetration into the structure.

The experimental and numerical study by Johnson and Holzapfel (2003) focused more on the structural modelling aspect of the bird strike event. In their investigation, the structure was modelled as a multi-layered shell element skin. The bird, made of gelatine and modelled using the SPH method, impacted the leading edge of an aircraft component at a velocity of $200 \mathrm{~m} / \mathrm{s}$. A similar approach to the other studies was followed, regarding the bird modelling validation. It was found that in the velocity range of $100-200 \mathrm{~m} / \mathrm{s}$, the composite delamination and ply failure were important and dependent on the impact energy level. It was concluded that the simulation technique of SPH for the bird and shell elements for the structure, is a promising discretization method.

Based on the above-mentioned experimental and numerical research work, the study herein assumed the SPH modelling technique for the bird. Initially, a numerical model verification phase was conducted, benchmarking against experimental and other numerical results available in the public domain, process described in the following section.

\section{SPH Bird Strike Modelling Verification}

Bird strike numerical modelling aims to generate the same impact load on the impacted structural component, in terms of pressure versus time across the impacted area, which varies in time as well. Hopkins and Kolsky (1960) distinguished between five different impact categories for the behaviour of the impactor named elastic, plastic, hydrodynamic, sonic and explosive. The bird material under similar energy impacts to this study, behaves like a fluid element and for that reason, the hydrodynamic category has been found to be the most appropriate description (Wilbeck 1978). For deciding the shape of the bird projectile, Hedayati \& Ziaei-Rad (2011) presented a comparison study between three available bird-modelling methods of Lagrangian, ALE and SPH, which were then further compared against the experimental test data produced by Wilbeck (1978). The bird shape, shown in fig.1, had a hemi-spherical ended cylinder geometry. It was identical for all three methods and for finer mesh discretization, all three approaches predicted results relatively close to the experimental ones. In accordance with current standard practice for bird strike modelling (McCarthy et al. 2004), the bird geometry in the current study was designed as a circular cylinder with hemispherical ends, with a cylinder length to diameter ratio equal to two. 
Figure 1: Geometric representation of a bird numerical model

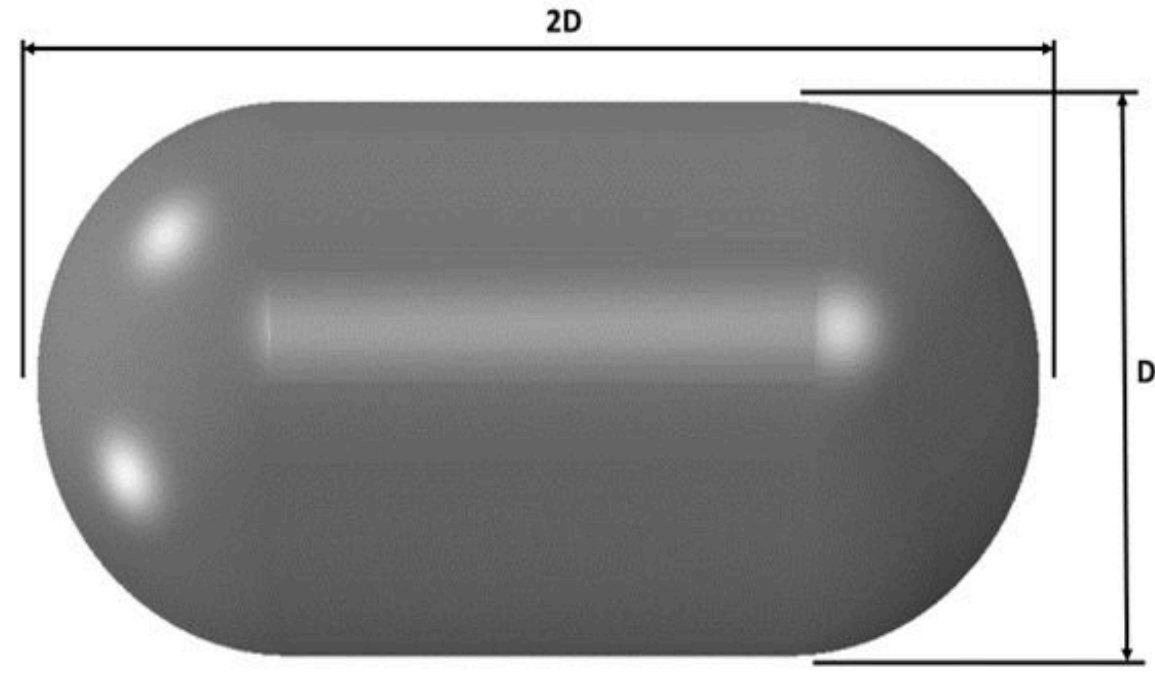

A few key parameters controlling the SPH material properties for bird modelling are needed as input in the ABAQUS® software platform, shown in table 1 and obtained from Wilbeck (1978), McCarthy et al. (2004) and Hedayati \& Sadighi (2016). The bird model is assumed to having density of $950 \mathrm{~kg} / \mathrm{m} 3$, due to the assumption of the bird material estimated to be air filled gelatine with $10 \%$ porosity, value measured experimentally by Barber et al. (1978). The bird mass was defined by airworthiness certification specification CS 25.631 , to be $1.82 \mathrm{~kg}(4 \mathrm{lb})$. In order to achieve the required mass, the bird's diameter D, was determined equal to $113 \mathrm{~mm}$, with a similar diameter value also reported in Langrand et al. (2002).

Table 1: SPH bird material modelling parameters

\begin{tabular}{l|r} 
SPH parameters (ABAQUS) & Value \\
\hline Bird material density, $\rho$ tonne $/ \mathrm{mm}^{3}$ & $9.5 \mathrm{e}-10$ \\
\hline Bird material speed of sound, $\mathrm{C}_{\mathrm{o}} \mathrm{mm} / \mathrm{s}^{2}$ & $1,482,900$ \\
\hline Grüneisen gamma, $Y_{\circ}$ & 0.1 \\
\hline Material constant-Gelatine, $\mathrm{S}$ & 2.0 \\
\hline
\end{tabular}

For the bird numerical modelling validation, simulations were run similar to the analysis of Hedayati \& Ziaei-Rad (2011) and compared against the experimental testing from Wilbeck (1978), shown in fig.2 and fig.3, where a circular steel plate of $60 \mathrm{~cm}$ in diameter and $6 \mathrm{~mm}$ in thickness was used as target. In the simulation, the plate consisted of 17280 linear 
hexahedral C3D8R solid elements having properties of steel. The number of SPH particles resulted from the bird meshing were around 8,000 . The peak pressure on the target plate imposed by the bird was captured as pressure fluctuation on the central plate node. The bird and target plate interaction was established using a node to surface contact.

Figure 2: Numerical validation model for the SPH modelling parameters

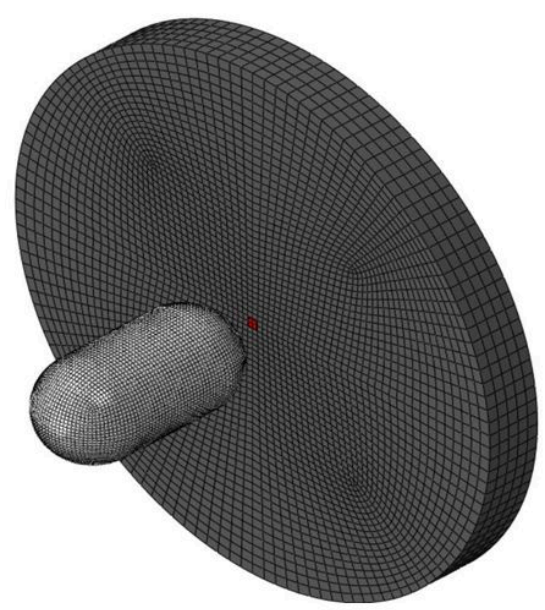

Figure 3: SPH bird model deformation at different time instants

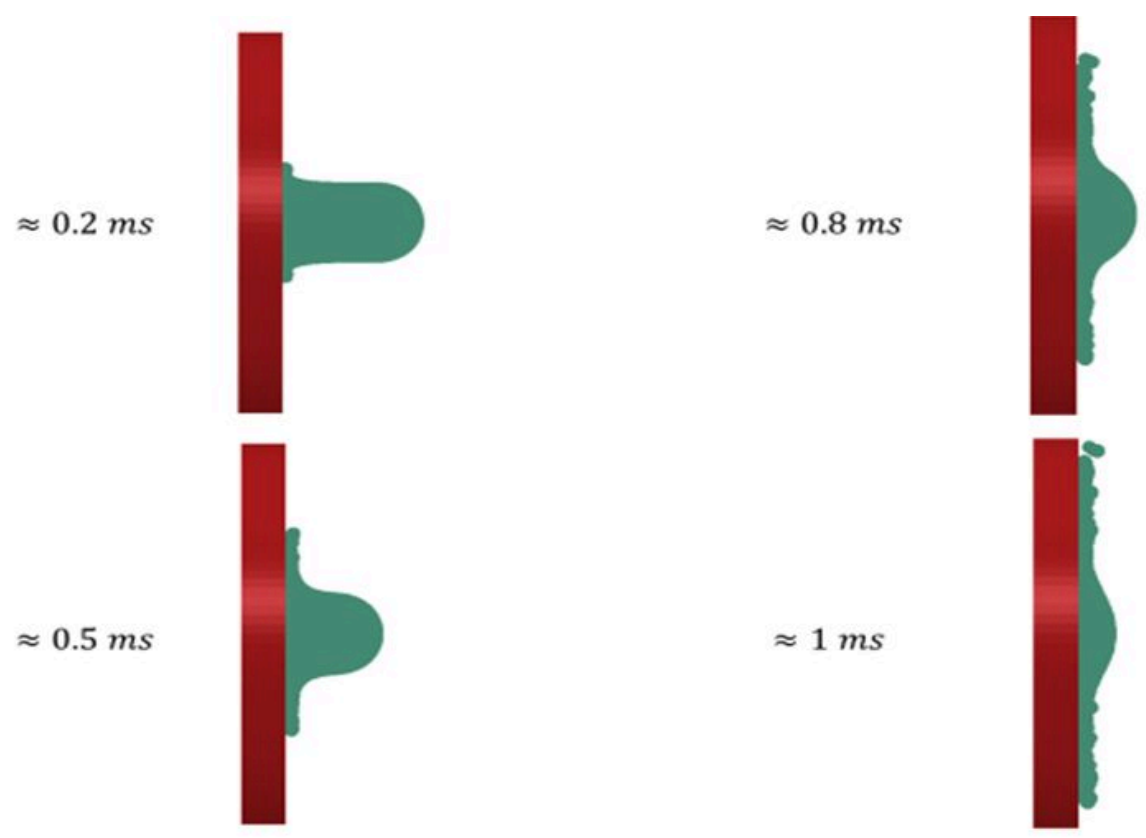

The bird model validation was performed by visual comparison of the SPH particles flow during the impact on the target with other literature findings, and by the pressure versus time variation at the center of the impacted plate. The flow of the 
bird particles was compared to the study by Hedayati \& Ziaei-Rad (2011), with the flow particle showing strong similarities. Additional validation tests with birds having a mass of $0.32 \mathrm{~kg}$ were also conducted. The bird diameter for the second case was set to $62.2 \mathrm{~mm}$ with the same geometric proportions, and an impact velocity of $116 \mathrm{~m} / \mathrm{s}$. The results obtained were in good agreement with the simulation results of Hedayati \& Ziaei-Rad (2011).

Figure 4 presents the pressure versus time of the impact, scaled accordingly for direct benchmark against the reported values in Wilbeck (1978) and Hedayati \& Ziaei-Rad (2011).

Figure 4: Target plate pressure profile for $1.82 \mathrm{~kg}$ and $0.32 \mathrm{~kg}$ birds

\section{Pressure Data / 1.82 kg Bird Strike}

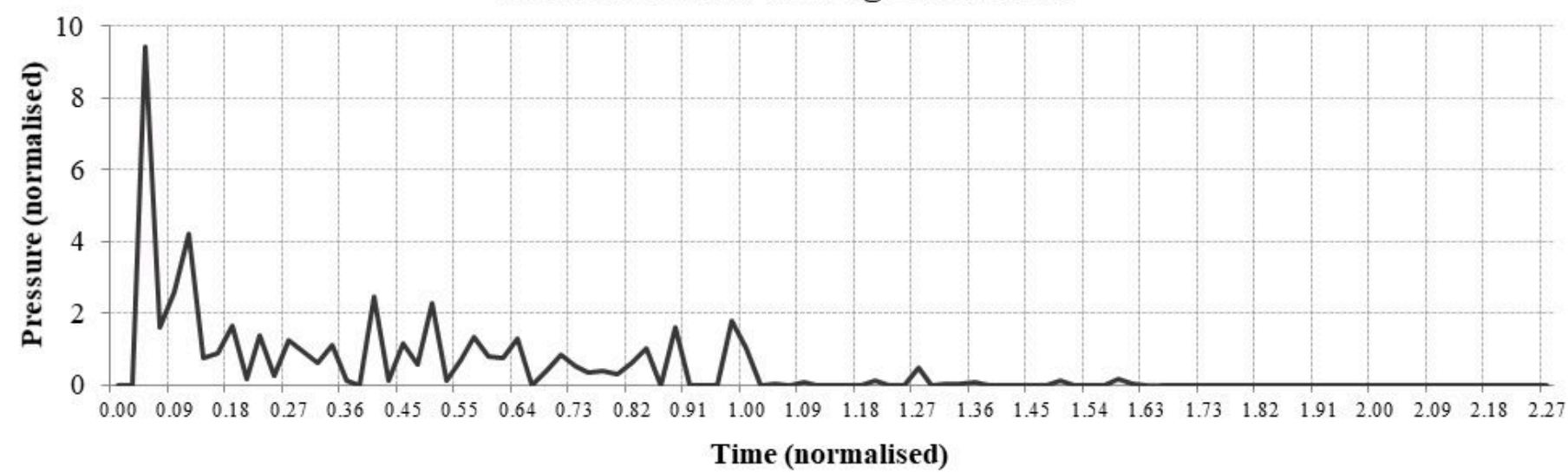

\section{Pressure Data / 0.32 kg bird Strike}

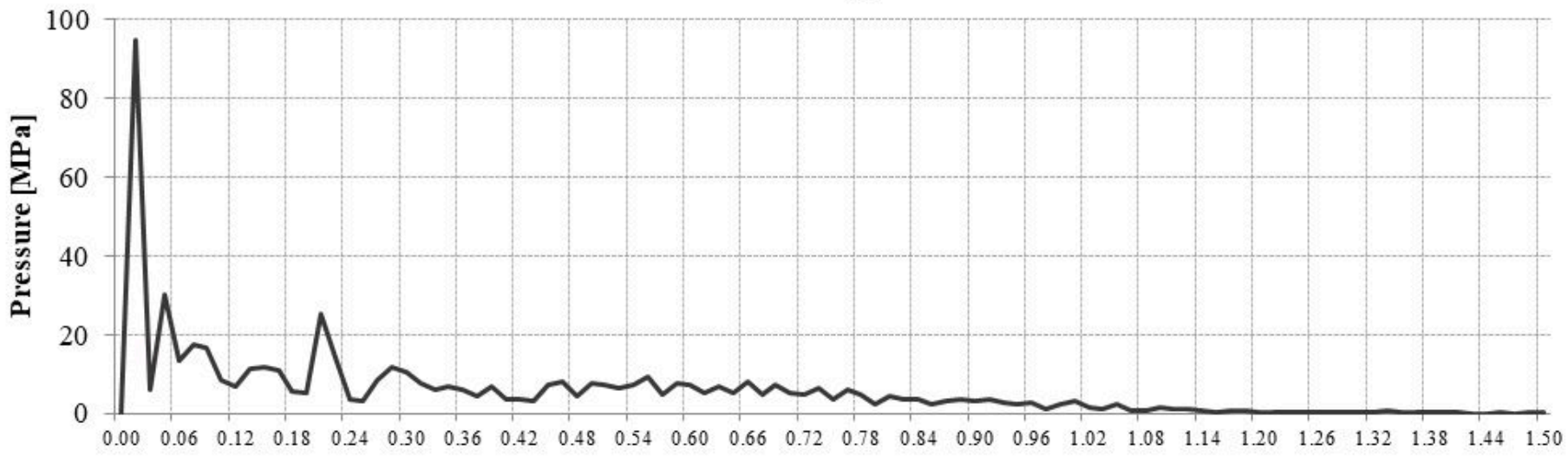

Time $[\mathrm{ms}]$

Peak pressure occurred initially and the pressure profile remaining stable with some fluctuations until complete disintegration of the projectile. The peak pressure from the author's simulation was captured at 94.9MPa, while Hedayati \& Ziaei-Rad (2011) reported it at $103.9 \mathrm{MPa}$. The simulations conducted for the actual bird size and mass of $1.82 \mathrm{~kg}$ were in good agreement as well. In these, simulations the bird velocity was set to $171 \mathrm{~m} / \mathrm{s}$, so that the same conditions with the literature studies were applied. The number of SPH particles resulted from this bird's mesh was found to be approximately 
43,000. In this case, the pressure and time results were normalized, as the literature results were presented in a

normalized form. Time was normalized using the expression $t_{N}=\frac{t V_{0}}{2 D}$, with $\mathrm{t}$ the actual time, Vo the bird's initial speed and

D the diameter of the cylinder model, while pressure was normalized using the expression $P_{N}=\frac{P}{\frac{1}{2} \rho_{0} V_{0}^{2}}$, where the normalized pressure is that actual pressure versus a dynamic head comprising of the initial density and speed of the bird. The pressure results for this simulation were compared to Wilbeck's (1978) experimental tests, as well as Heimbs FE model (2011).

The above benchmarking procedure provided with enough confidence in the SPH modelling strategy and parameters adopted for the simulations performed on virtual LE structures.

\section{Structural Material Energy Absorption Mechanisms}

The materials used in the structural modelling were aluminium 2024-T3, GLARE, which is a layered material with alternating aluminium and glass fibre, reinforce epoxy layers, and IM7/8552 carbon fibre reinforced composite. Apart from the elastic structural deformation for accommodating the energy of the impact, two different material failure energy absorption mechanisms were numerically modelled; a) plasticity modelling for the aluminium skin and the aluminium GLARE layers, and b) damage initiation followed by a linear reduction in the stiffness damage propagation mechanism for the glass and carbon fibre composites (ABAQUS $®$ analysis user guide 2014). The elastic mechanical properties for the aluminium were obtained from MIL-HDBK 5J (2003), while the Johnson-Cook ductile damage plasticity criterion was included in the simulation according to eq.(1) and table 2, found in the work of Wierzbicki et al. (2005):

$$
\bar{\varepsilon}_{0 i}=\left[D_{1}+D_{2} \exp \left(D_{3} \frac{P}{\bar{\sigma}}\right)\right]
$$


Table 2: Material properties for aluminium 2024-T3

\begin{tabular}{l|r} 
Property & Value \\
\hline Density, $\rho \mathrm{kg} / \mathrm{m}^{3}$ & 2760 \\
\hline Elastic Modulus, E GPa & 74 \\
\hline Poisson's Ratio, $\mathrm{v}$ & 0.33 \\
\hline Johnson-Cook eq. parameter $\mathrm{D}_{1}$ & -0.07 \\
\hline Johnson-Cook eq. parameter $\mathrm{D}_{2}$ & 1.02 \\
\hline Johnson-Cook eq. parameter $\mathrm{D}_{3}$ & -1.62 \\
\hline
\end{tabular}

The area underneath the stress strain elastoplastic material response assumed by eq.(1), is a measure of the material's capacity to absorb energy, by transforming it into material plasticization.

The mechanical properties for the fibre-reinforced composites implemented, the S2 glass fibre as [0/90] layers and the IM7/8552 are tabulated in table 3, as reported in Wierzbicki et al. (2005), Ghafarizadeh et al. (2016), Tomblin and Hopper (2011):

Table 3: Material properties for the fibre reinforced composite laminates

\begin{tabular}{|c|c|c|}
\hline Material Property & S2 Glass & IM7/8552 \\
\hline Density, $\rho \mathrm{kg} / \mathrm{m}^{3}$ & 1,960 & 1,780 \\
\hline Longitudinal Young's Modulus, $\mathrm{E}_{1} \mathrm{MPa}$ & 53,000 & 158,500 \\
\hline Transverse Young's Modulus, $\mathrm{E}_{2} \mathrm{MPa}$ & 16,000 & 8,963 \\
\hline In-Plane Shear Modulus, $\mathrm{G}_{12} \mathrm{MPa}$ & 6,000 & 4,688 \\
\hline Poisson's Ratio, v & 0.28 & 0.33 \\
\hline Longitudinal Tensile Strength, $\mathrm{S}_{\mathrm{t} 1} \mathrm{MPa}$ & 1,590 & $2,500.65$ \\
\hline Longitudinal Compressive Strength, $\mathrm{S}_{\mathrm{c} 1} \mathrm{MPa}$ & 690 & $1,731.48$ \\
\hline Transverse Tensile Strength, $\mathrm{S}_{\mathrm{t} 2} \mathrm{MPa}$ & 41 & 64.05 \\
\hline Transverse Compressive Strength, $\mathrm{S}_{\mathrm{c} 2} \mathrm{MPa}$ & 110 & 285.71 \\
\hline Longitudinal Shear Strength, $\mathrm{S}_{\mathrm{L}} \mathrm{MPa}$ & 62 & 4.68 \\
\hline Transverse Shear Strength, $\mathrm{S}_{\mathrm{T}} \mathrm{MPa}$ & 55 & 4.68 \\
\hline Longitudinal Tensile Fracture Energy, $\mathrm{G}_{\mathrm{FT}} \mathrm{kJ} / \mathrm{m}^{2}$ & {$[0 / 90] 3.5^{*}$} & 91.6 \\
\hline Longitudinal Compressive Fracture Energy, $\mathrm{G}_{\mathrm{FC}} \mathrm{kJ} / \mathrm{m}^{2}$ & {$[0 / 90] 3.5^{*}$} & 79.9 \\
\hline Transverse Tensile Fracture Energy, $\mathrm{G}_{\mathrm{MT}} \mathrm{kJ} / \mathrm{m}^{2}$ & - & 0.22 \\
\hline Transverse Compressive Fracture Energy, $\mathrm{G}_{\mathrm{MC}} \mathrm{kJ} / \mathrm{m}^{2}$ & - & 1.1 \\
\hline
\end{tabular}


For both fibre reinforced composites, the Hashin damage criterion was assumed for failure initiation, shown in equations (2)-(5), while damage propagate based on a bilinear fracture propagation law, with damage initiation and fracture toughness values for damage propagation tabulated in table 3 as well.

$$
\begin{gathered}
F_{f}{ }^{t}=\left(\frac{\sigma_{11}}{S_{t 1}}\right)^{2}+\mathrm{a}\left(\frac{\sigma_{12}}{S_{s 12}}\right)^{2} \leq 1.0 \text { and } \sigma_{11} \geq 0 \\
\mathrm{~F}_{\mathrm{f}}{ }^{\mathrm{c}}=\left(\frac{\sigma_{11}}{\mathrm{~S}_{\mathrm{c} 1}}\right)^{2} \leq 1.0 \text { and } \sigma_{11}<0 \\
\mathrm{~F}_{\mathrm{m}}{ }^{\mathrm{t}}=\left(\frac{\sigma_{22}}{\mathrm{~S}_{\mathrm{t} 2}}\right)^{2}+\left(\frac{\sigma_{12}}{\mathrm{~S}_{\mathrm{s} 12}}\right)^{2} \leq 1.0 \text { and } \sigma_{22} \geq 0 \\
\mathrm{~F}_{\mathrm{m}}{ }^{\mathrm{c}}=\left(\frac{\sigma_{22}}{2 \mathrm{~S}_{\mathrm{s} 23}}\right)^{2}+\left[\left(\frac{\mathrm{S}_{\mathrm{c} 2}}{2 \mathrm{~S}_{\mathrm{s} 23}}\right)^{2}-1\right] \frac{\sigma_{22}}{\mathrm{~S}_{\mathrm{c} 2}}+\left(\frac{\sigma_{12}}{\mathrm{~S}_{\mathrm{s} 12}}\right)^{2} \leq 1.0 \text { and } \sigma_{22}<0
\end{gathered}
$$

These equations represent the points of material failure initiation. By assuming a linear decrease in the material internal resistance to externally applied additional deformation after failure initiation, the measure of energy absorption transforming into the material damage, termed as the material fracture toughness, is then represented by the area sketched underneath the stress deformation bilinear relationship.

\section{Bird Impact on Curved, Leading-Edge Form}

The finite element model developed for investigating the relative effects of the skin material, skin thickness and rib positioning to the leading-edge structural integrity under bird strike is shown in fig.5. The model is representative of a typical wing LE section and it comprised of an outer skin panel, two ribs and a spar. 
Figure 5: Representative wing LE structure modelled in ABAQUS
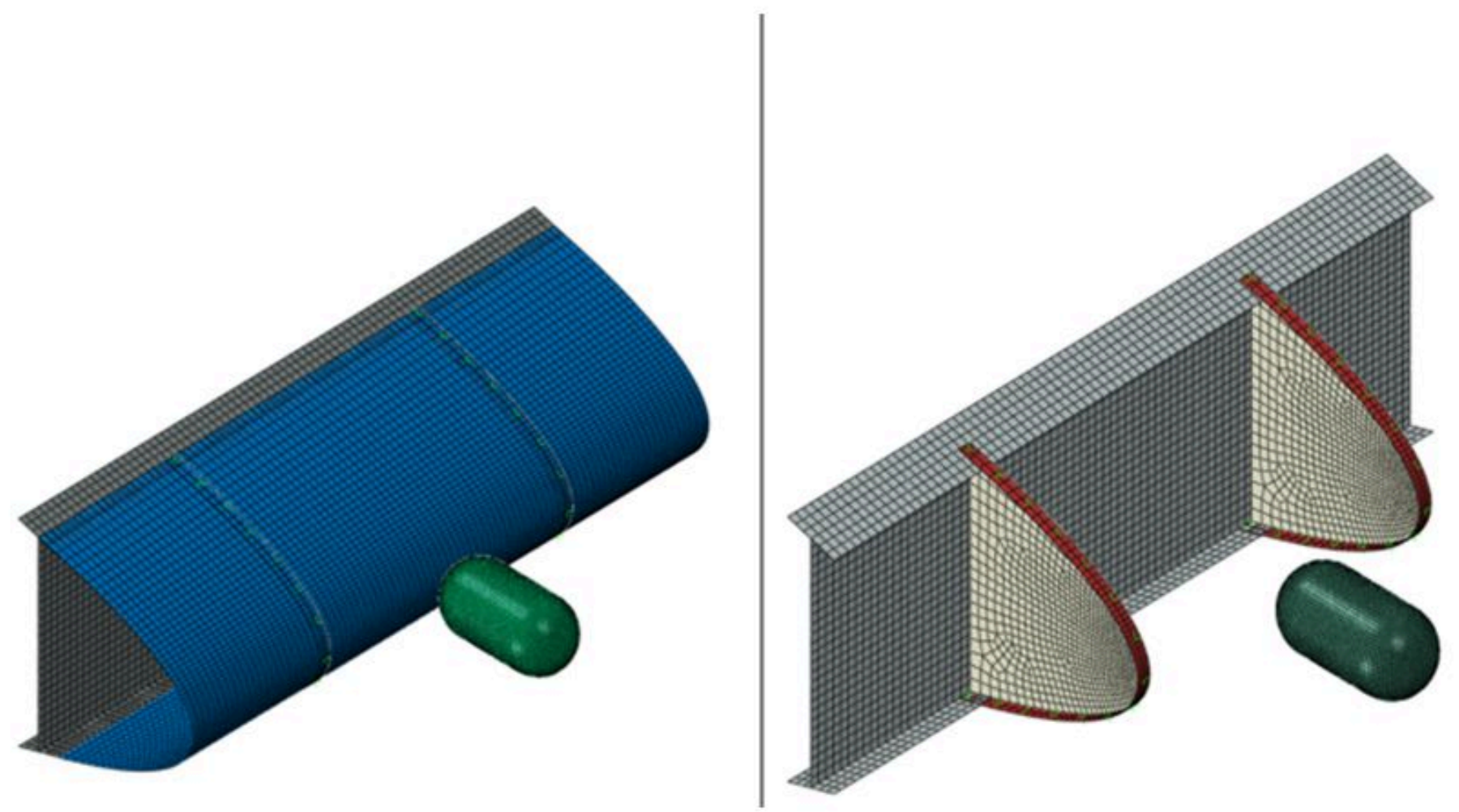

Fastener attachments were encompassed in the model for a realistic rib attachment to the skin panel, using a built-in function within the software. The skin panel span was set to $1000 \mathrm{~mm}$ with a finite element mesh consisting of $7200 \mathrm{~S} 4 \mathrm{R}$ linear quadrilateral elements. The spar and ribs material was selected to be aluminium alloy 2024-T3, irrespective of the choice of the skin material. The spar web and flange thicknesses were both set at $2.5 \mathrm{~mm}$. Constant thicknesses throughout the simulations were assigned to the rib web and flange, $1.75 \mathrm{~mm}$ and $1 \mathrm{~mm}$ respectively, so that the results would be solely dependent on the LE skin material and thickness. The bird's impact velocity was set to $180 \mathrm{~m} / \mathrm{s}$ and the total simulation time was set at $0.004 \mathrm{sec}$, to allow enough time for the impact to be fully absorbed by the structure, as shown in fig.6. 
Figure 6: Representative LE total deformation following the bird strike event
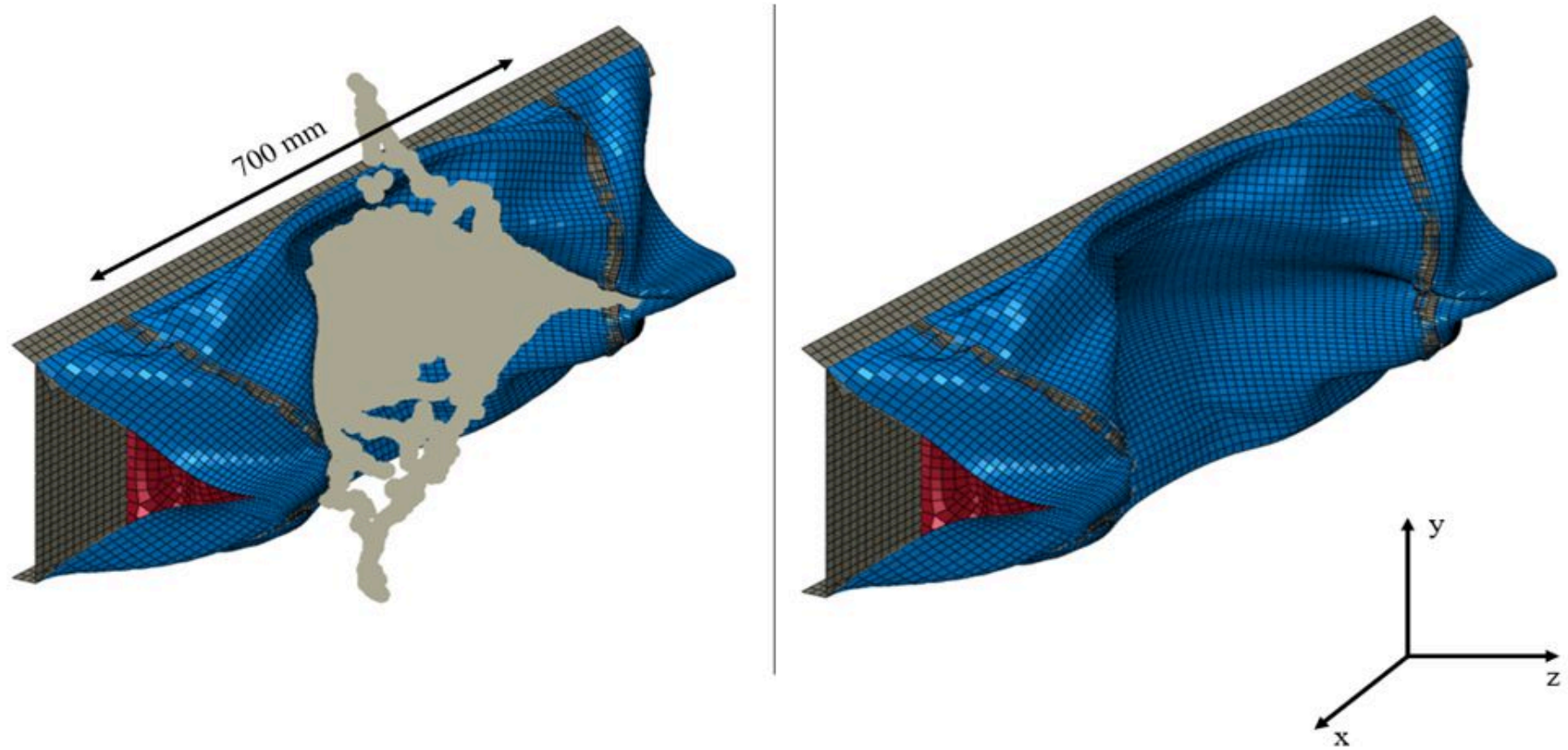

Simulations were run and results were obtained in terms of three rib positions, namely at $300 \mathrm{~mm}, 500 \mathrm{~mm}$ and $700 \mathrm{~mm}$ spacing and for the three different skin materials, aluminum alloy 2024-T3, GLARE and IM7/8552. The FML laminate is produced in pre-specified layups, five of which were chosen for analysis, shown in table 4.

Table 4: Skin thickness values in $\mathrm{mm}$ for the three materials used

\begin{tabular}{c|c|c|c} 
GLARE Configuration & GLARE & Aluminum alloy 2024-T3 & IM7-8552 \\
\hline 2/1 Plies & 1.06 & 1.00 & 1.55 \\
\hline 3/2 Plies & 1.73 & 1.58 & 2.47 \\
\hline 4/3 Plies & 2.40 & 2.17 & 3.40 \\
\hline 5/4 Plies & 3.06 & 2.76 & 4.33 \\
\hline 6/5 Plies & 3.73 & 3.35 & 5.25
\end{tabular}

The other two skin materials thicknesses for the LE, the skin made of aluminium and of IM7/8552 were chosen in thickness to match the GLARE skin predefined weight. Table 4 is depicting the skin material thicknesses that result in the same total LE weight.

The numerical simulations results are depicted in figures 7, 8 and 9, were the spar permanent residual deformation is plotted against the LE skin thickness, for the three materials used. It has to be stretched that the results are governed by the numerical implementation of the material damage modelling for the aluminium and composite materials. 
Figure 7: Spar residual deformation versus skin thickness for the Aluminium LE

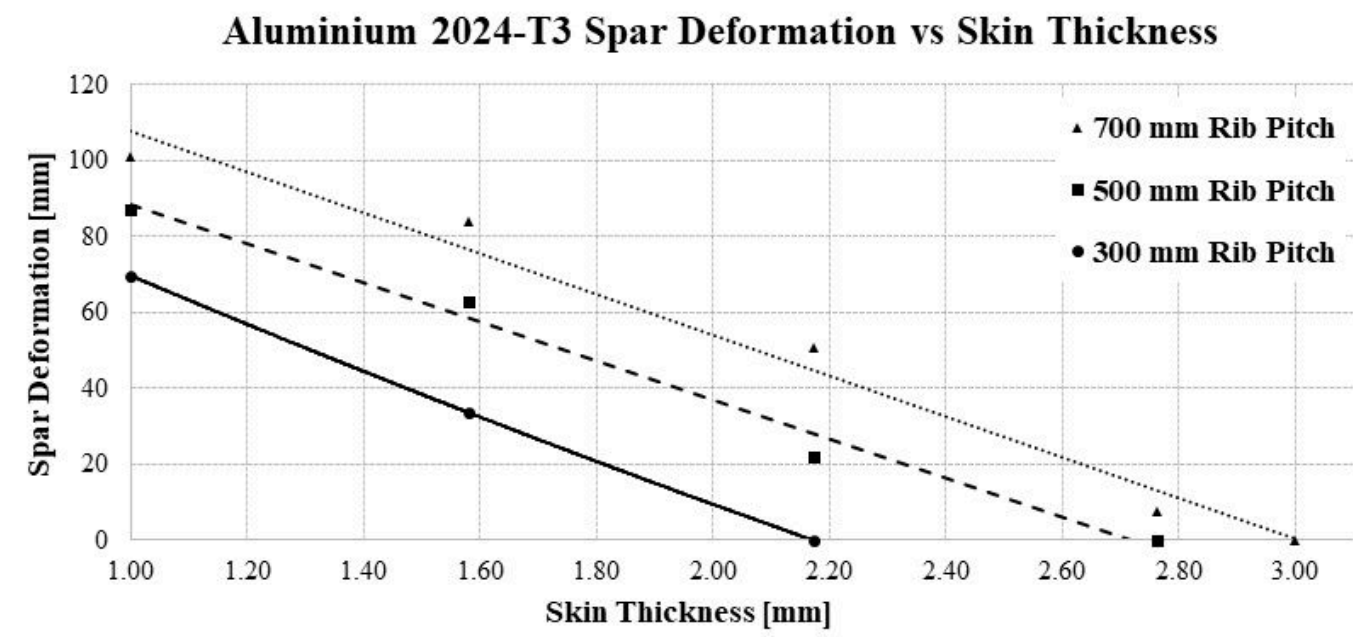

Figure 8: Spar residual deformation versus skin thickness for the GLARE LE

\section{GLARE Spar Deformation vs Skin Thickness}

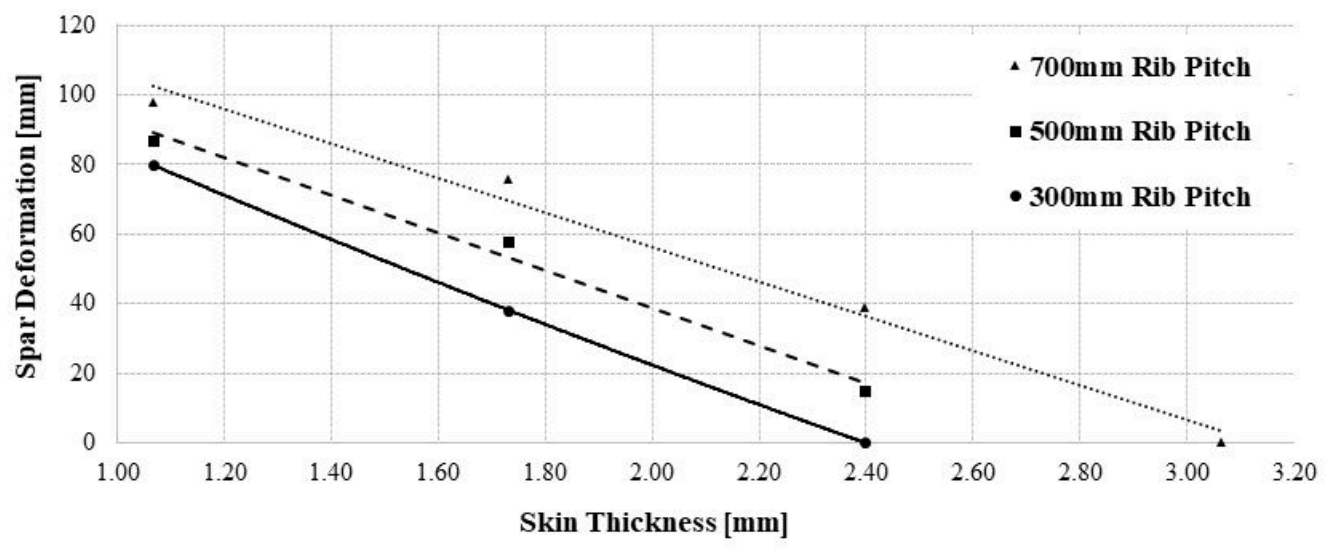

Figure 9: Spar residual deformation versus skin thickness for the IM7/8552 LE

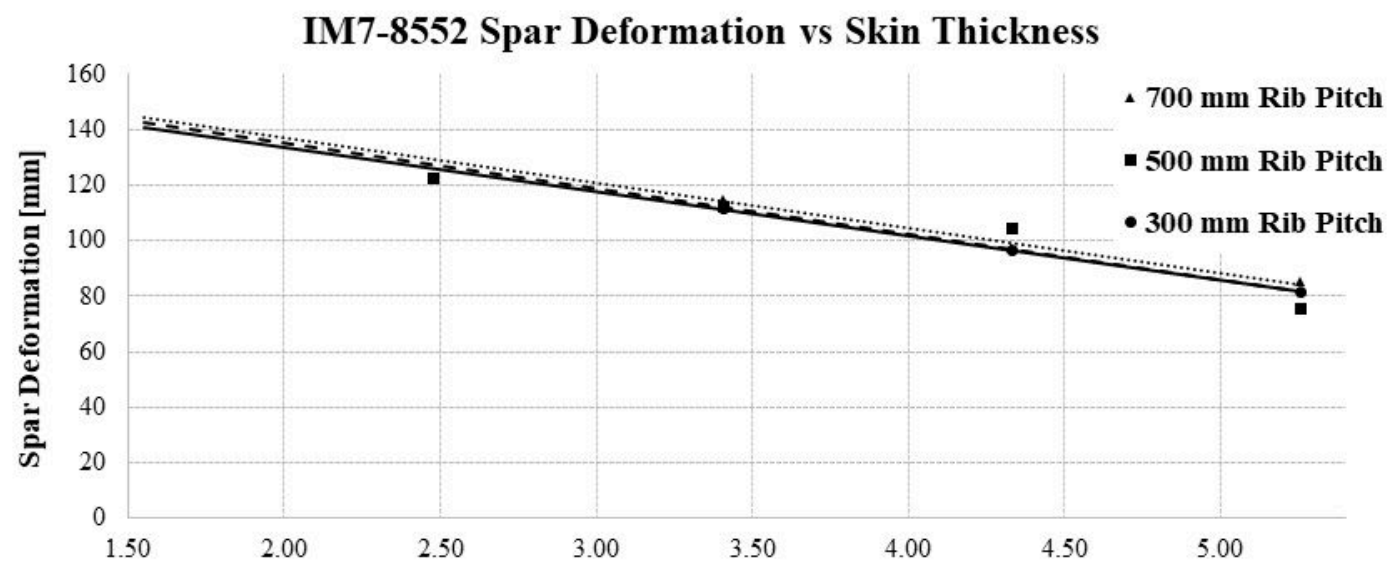

Skin Thickness [m] 
Hence, based on the numerical modelling strategy followed, it was found that the aluminium alloy and GLARE panels behaved in a similar manner, having higher impact energy absorption capacity, with the aluminium being slightly more effective than GLARE. On the other hand, the aluminium skin panel penetration along the projectile motion was deeper than for the GLARE panels. This impact resistance benefit of GLARE is important from an airworthiness requirement standpoint, taking into account the Acceptable Means of Compliance AMC 25.631, since lower component deformations result in lower chances of internal structure damage due to impact. The IM7/8552 was less successful than the other two materials. The numerically modelled composite skin was unable to resist and absorb the bird's kinetic energy during all cases, resulting at a considerable spar web deformation. It was found that the bird's frontal segment was only partially fragmented upon contact with the composite skin, which was then instantly penetrated.

\section{Semi-Empirical Methods}

Semi-empirical skin thickness prediction methods for wing and tail-plane leading-edge panels can be found in the literature, to aid with bird strike structural performance analysis. Such methods are mainly suitable for application during the preliminary design stages. Prof Howe (2004) quoted semi-empirical equations (6) and (7), originally referenced in the Royal Aerospace Establishment Report TR 72056 (McNaughtan 1972). The formulation is capable of estimating the required metallic skin thicknesses for bird strike requirements initial compliance. Considering the growing usage of composite materials in current aircraft designs, the applicability spectrum of the method is rather limited.

$$
\begin{aligned}
& t_{\text {skin }}=0.02 V_{M} m^{1 / 3} f(\text { Mat }) \cos \theta^{2 / 3} /\left[\exp \left\{1230 /\left(r^{2}+30 r+1000\right)\right\}\right] \\
& f(\text { Mat })=0.8\left[330 / f_{1}(\text { Mat })\right]
\end{aligned}
$$

\section{Case Study: Virtual Bird Strike Testing of Cranfield E-19 Wing LE}

The Cranfield E-19 supersonic business jet aircraft displayed in fig.10, is an aircraft preliminary design study, performed in 2019 at Cranfield University as a student project. 
Figure 10: Cranfield E-19 Supersonic Business Jet

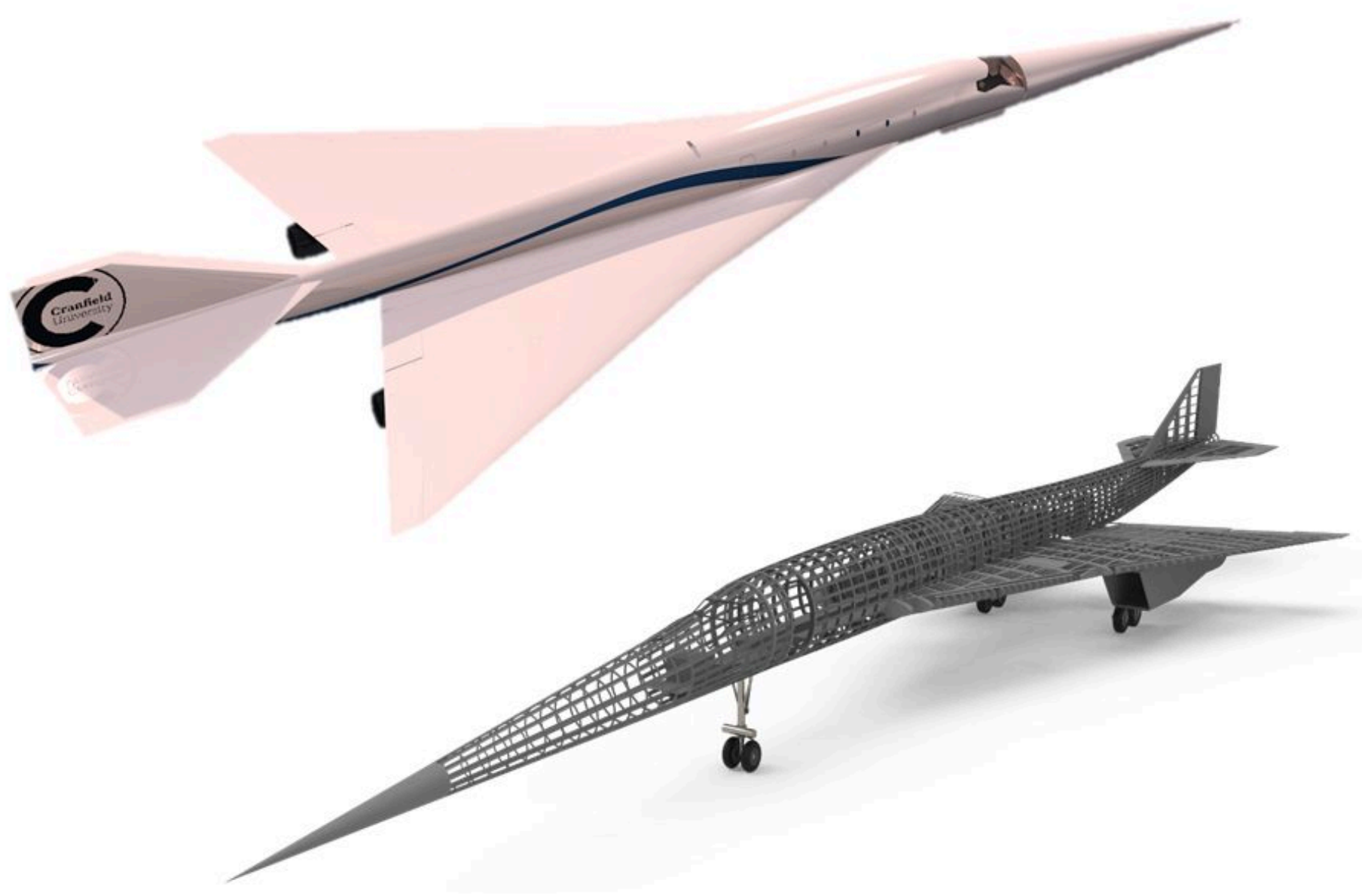

It is common practice for structural designers during preliminary studies to use analytic methods for estimating the leading-edge skin thicknesses, excluding the effects of rib support and rib pitch. The E-19 wing leading-edge geometry was used for the development of the skin thickness/material and rib pitch correlation, as well as a means to perform a correlation and validation study with the semi-empirical analytic equations available in the literature.

The E-19 jet was designed to cruise at Mach 1.95 resulting in a delta wing geometry. The structural design of the E-19 wing LE consisted of a double spar configuration with multiple ribs, as shown in fig.11. 
Figure 11: Typical wing LE device internal structure
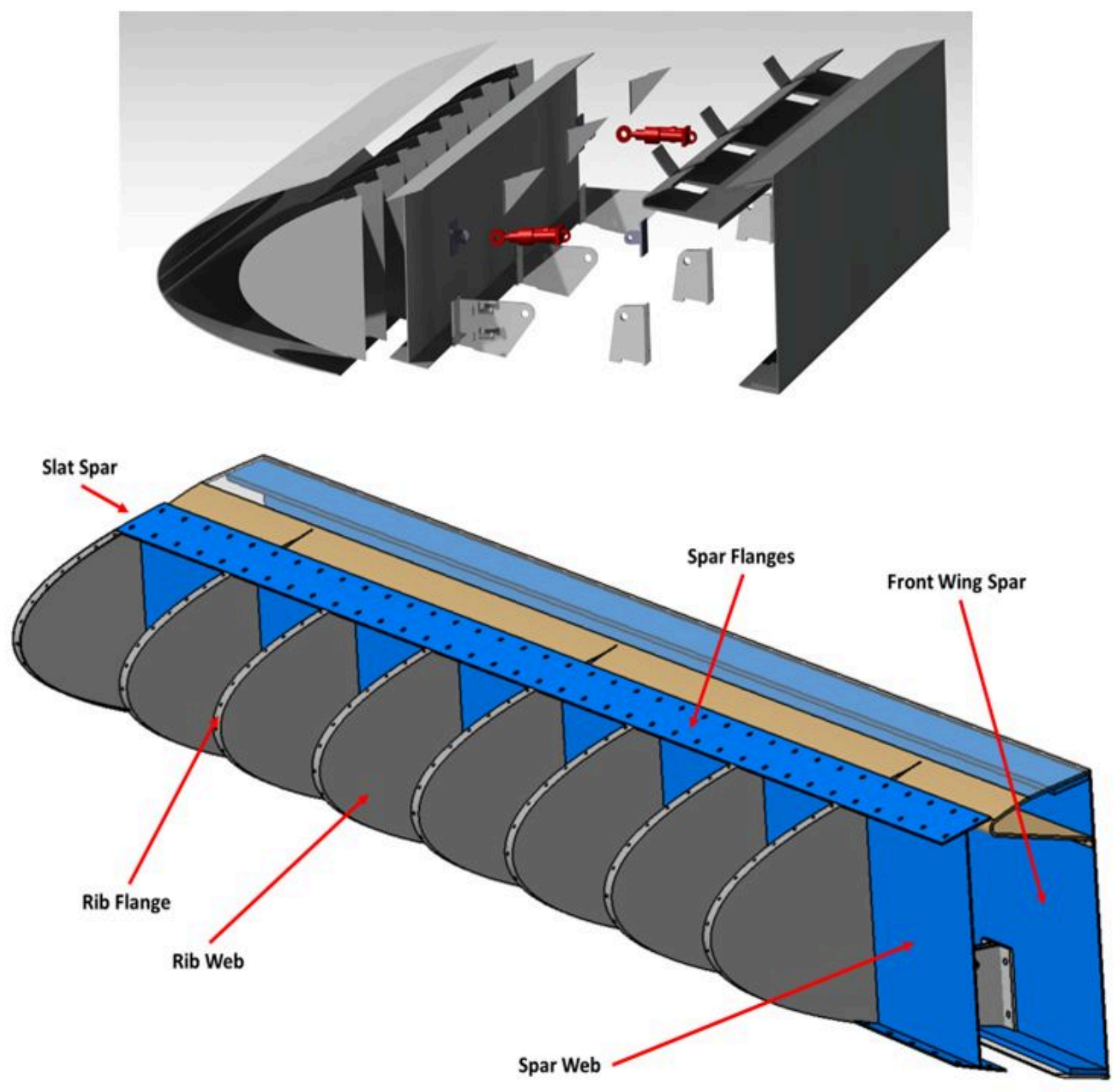

The space between the slat spar and the front wing spar for accommodating the drooping mechanism, packed the hinges and actuators. According to AMC 25.631, the component positioning should be conducted with respect to bird strike in the early design stages. The airworthiness requirements also state that installation of items essential to operations, such as actuators, and items that if damaged could cause hazard, should be protected as far as practicable. In a wing design where there is no deployable leading-edge device, the above requirement translates to no penetration of the front wing 
spar being allowed. In E-19's case study, where a leading-edge device exists, for preliminary design purposes, the requirement was translated as not allowing any permanent residual deformation of the slat spar.

\section{Virtual Testing Cases of E-19 Leading-Edge}

The virtual testing of the E-19's LE wing was established through five different bird locations and positions relative to the slat structure proposed. Based on the previous analysis of bird strike on a generic leading-edge form, the material used was GLARE. The bird velocity was $180 \mathrm{~m} / \mathrm{s}$ calculated by CS 25.631 , in accordance to E-19 flight envelope. Two head-on collision simulations were run, with the bird being positioned in the middle of two adjacent ribs in the first one, shown in fig.12.a, and the bird being positioned in line with the structure's mid-rib in the second one, shown in fig.12.b.

Figure 12: Bird strike along the flight direction a) in between rib support, b) at rib location

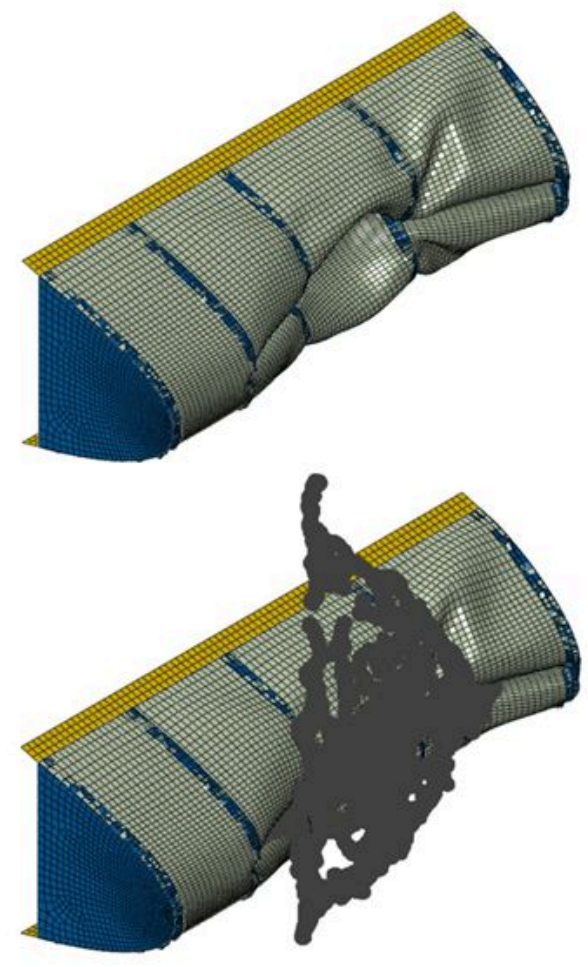

a

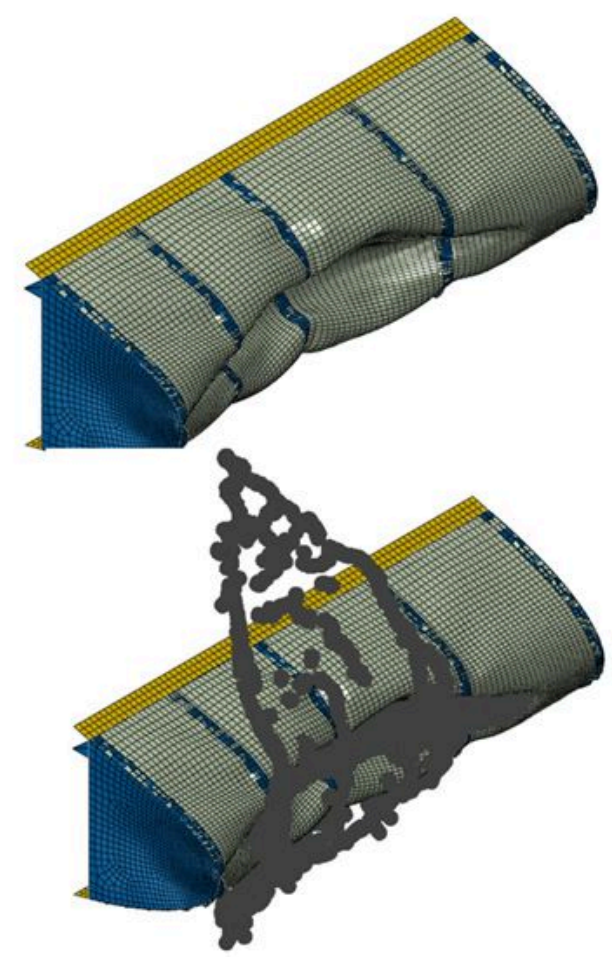

$\mathrm{b}$

The second set of testing focused on the bird's impacting angle, with the first one having the bird impacting the structure at a 300 angle from the lower skin part, in fig.13.a, and the second one having the bird impacting the structure at a 450 angle relative to the slat span, shown in fig.13.b. In the above-mentioned simulation setups, the velocity vector was 
always perpendicular to the slat surface. However, the 450 angle relative to the slat span simulation was rerun with a velocity vector in line with the bird's angle to investigate the effects of shear on the skin and rib bending in the span-wise direction, shown in fig.13c.

Figure 13: Bird strike in between rib support at a) $30^{\circ}$ below to the flight direction, b) and c) at $45^{\circ}$ to the flight direction
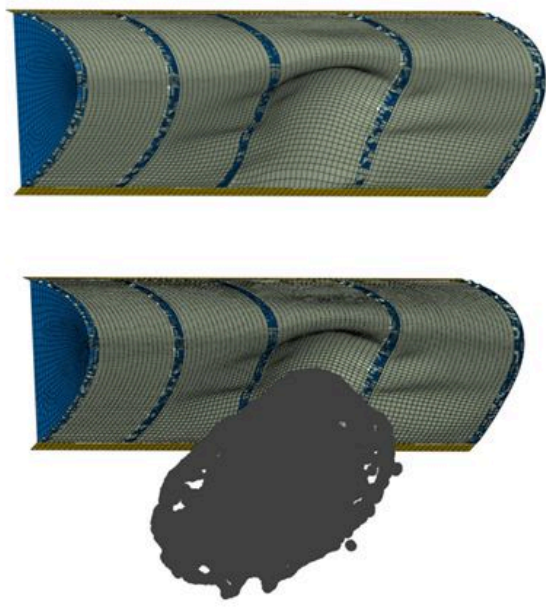

a
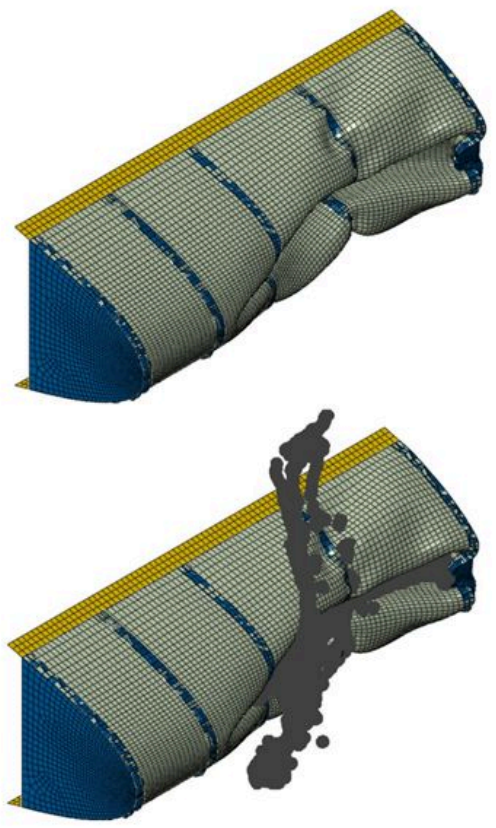

b
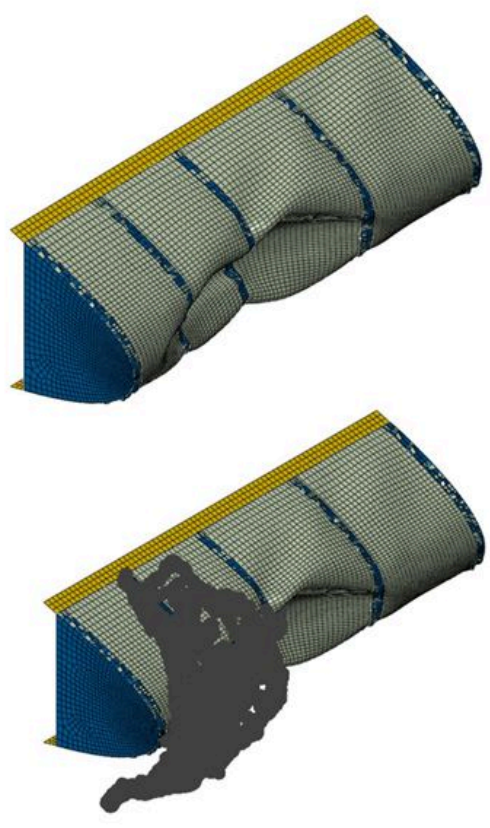

C

The skin material thickness was $3.06 \mathrm{~mm}$, which resulted in GLARE 5/4 configuration. The rib pitch chosen was at about $320 \mathrm{~mm}$. In order to validate the semi-empirical equation suggested, the skin thickness made of aluminium alloy 2024-T3 was estimated to be $1.78 \mathrm{~mm}$.

\section{Case Study Results}

The results obtained revealed that no penetration of the skin occurred in any of the simulations. The largest deformation of the skin panel was recorded in the impact target at the two adjacent ribs case at $227 \mathrm{~mm}$ and the lowest one was captured in the in line with the structure's mid-rib case. The heavily deformed FML panel managed to absorb the bird's kinetic energy, while material damage/failure was only found in the S2 glass composite laminate sections. The bird's 
fragments managed to be deflected by the structure, securing the spar web from deforming and proving the structure's compliance.

The outcome of the semi-empirical equation validation study showed that the skin material/thickness and rib pitch did not provide adequate structural strength to deflect the bird and prevent the critical structural components for the flight safety from critically deforming. The simulation showed large deformations on the ribs' web and skin, and some residual deformation on the spar as well, shown in fig.14. It was evident that a deeper insight in the failure process could be gained by the numerical analysis tools.

Figure 14: Bird impact simulation with residual spar deformation

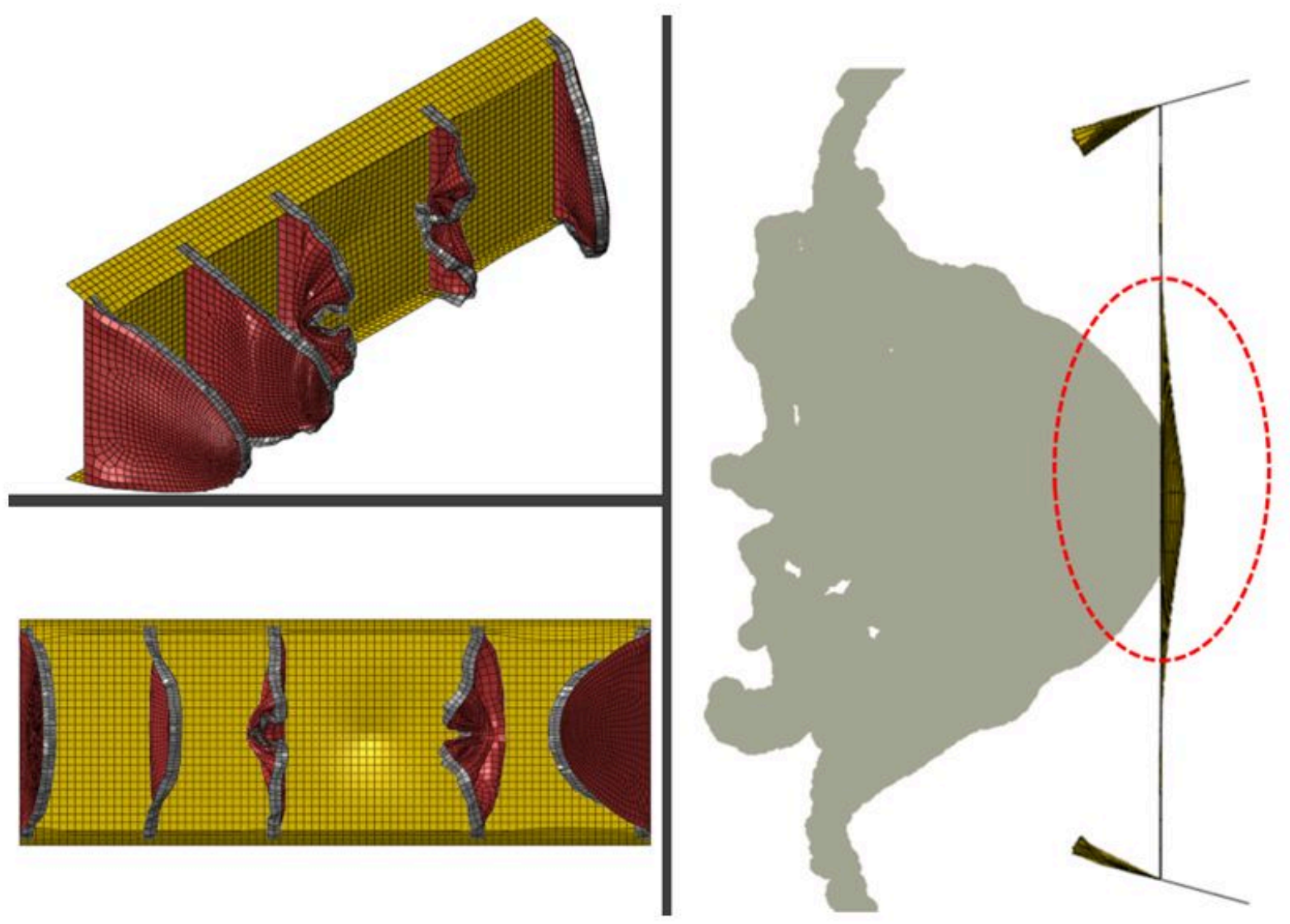

The charts developed initially from simulation run on a dummy leading-edge structure, could feed some interesting information for further development of the component and provide with critical insights early on in the design life cycle. 


\section{Conclusions}

The study herein, presented the SPH numerical modelling parameters and the path to verification of a numerical model for bird strike events simulations. Numerical results were benchmarked against experimental ones as well as correlated with similar studies, available in the public domain. Following the bird model verification, a number of simulations upon a representative leading-edge structure were performed and design charts were drawn correlating the skin leading-edge material and thickness with the rib positioning. Those charts were used for the preliminary design of E-19 aircraft wing leading edge.

- Simulations based on the applicable metal plasticity and progressive damage modelling for the composites, showed that the aluminium structure had a better capability of impact energy absorption, while GLARE was able to provide with smaller overall penetration. The carbon fibre leading-edge skin did not perform that well.

- The study illustrated the means of incorporating powerful software tools earlier in the design life cycle than fullscale experimental verification, were parametric design studies can lead to better products. Although these tools have not reached the maturity level to fully substitute testing for certification proofing, they can nevertheless provide with meaningful insight early on, avoiding costly re-designing processes.

\section{References}

Abaqus Analysis User's Guide, 6.14 (2014).

Alderliesten, R. (2017) Solid Mechanics and Its Applications Fatigue and Fracture of Fibre Metal Laminates. Springer . Available at: http://www.springer.com/series/6557.

Barber, J., Taylor, H. R. and Wilbeck, J. S. (1978) Bird Impact Forces and Pressures on Rigid and Compliant Targets.

Certification Specifications for Large Aeroplanes CS-25_Amendment 3 (2007) European Aviation Safety Agency.

Georgiadis, S., Gunnion, A. J., Thomson, R. S. and Cartwright, B. K. (2008) 'Bird-strike simulation for certification of the Boeing 787 composite moveable trailing edge', Composite Structures, 86(1-3), pp. 258-268.

doi: 10.1016/j.compstruct.2008.03.025.

Ghafarizadeh, S., Chatelain, J. F. and Lebrun, G. (2016) 'Finite element analysis of surface milling of carbon fiberreinforced composites', International Journal of Advanced Manufacturing Technology. Springer London, 87(1-4), pp. 399409. doi: $10.1007 / \mathrm{s} 00170-016-8482-y$. 
Hedayati, R. and Ziaei-Rad, S. (2011) 'A new bird model and the effect of bird geometry in impacts from various orientations', International Journal of Vehicle Structures and Systems, 3(3), pp. 184-191.

doi: 10.1016/j.ast.2012.09.002.

Hedayati, R. and Sadighi, M. (2016) Bird strike: an experimental, theoretical and numerical investigation. Cambridge: Woodhead Publishing in Mechanical Engineering.

Heimbs, S. (2011) 'Computational methods for bird strike simulations: A review', Computers and Structures, pp. 20932112. doi: 10.1016/j.compstruc.2011.08.007.

Heimbs, S. (2011) 'Bird Strike Simulations on Composite Aircraft Structures', in SIMULIA Customer Conference. Munich, Germany: EADS, Innovation Works.

High Strength Glass Fibers (2006). Available at: https://www.agy.com/wpcontent/uploads/2014/03/High_Strength_Glass_Fibers-Technical.pdf.

Hopkins H. G., and Kolsky H., 'Mechanics of Hypervelocity Impact of Solids', Proceedings of the Fourth Symposium on Hypervelocity Impact, Air Proving Ground Center, Eglin Air Force Base, Florida, 1960, paper no 12.

Howe, D. (2004) Aircraft loading and structural layout. London: Professional Engineering Publishing.

Johnson, A. F. and Holzapfel, M. (2003) 'Modelling soft body impact on composite structures', Composite Structures. Elsevier BV, 61(1-2), pp. 103-113. doi: 10.1016/S0263-8223(03)00033-3.

Kermanidis, T., Labeas, G., Sunaric, M. and Ubels, L. (2005) 'Development and validation of a novel bird strike resistant composite leading edge structure', Applied Composite Materials, 12(6), pp. 327-353. doi: 10.1007/s10443-005-3441-z. Langrand, B., Bayart, A. S., Chauveau, Y. and Deletombe, E. (2002) 'Assessment of multi-physics FE methods for bird strike modelling-Application to a metallic riveted airframe', International Journal of Crashworthiness 7(4), pp. 415-428.

McCarthy, M. A., Xiao, J. R., Mccarthy, C. T., Kamoulakos, A., Ramos, J., Gallard, J. P. and Melito, V. (2004) Modelling of Bird Strike on an Aircraft Wing Leading Edge Made from Fibre Metal Laminates-Part 2: Modelling of Impact with SPH Bird Model, Applied Composite Materials.

MacKinnon, B. (2004) Sharing the Skies. An Aviation Industry Guide to the Management of Wildlife Hazards, Sharing the Skies. An Aviation Industry Guide to the Management of Wildlife Hazards. Transport Canada.

McNaughtan I.I. , "The Design of Leading-Edge and Intake Wall Structure to Resist Bird Impact", Royal Aircraft Establishment T.R. 72056, AD-903942, Apr. 1972.

MIL-HDBK-5J, Department of Defense Handbook: Metallic Materials and Elements for Aerospace Vehicle Structures (31 January 2003) [S/S by MMPDS-01] 
Ng, Y., Tomblin, J. and Hooper, E. (2011) Hexcel 8552 IM7 Unidirectional Prepreg 190 gsm \&amp; 35\%RC Qualification Material Property Data Report FAA Special Project Number SP4614WI-Q Revision A. NATIONAL INSTITUTE FOR AVIATION RESEARCH.

Tho, C.-H. and Smith, M. R. (2008) ACCURATE BIRD STRIKE SIMULATION METHODOLOGY FOR BA609 TILTROTOR. Texas.

Wilbeck, J. S. (1978) 'Impact Behavior of Low Strength Projectiles', Air Force Flight Dynamics Laboratory, AFML-TR-77. Wierzbicki, T., Bao, Y., Lee, Y. W. and Bai, Y. (2005) 'Calibration and evaluation of seven fracture models', International Journal of Mechanical Sciences, 47(4-5 SPEC. ISS.), pp. 719-743. doi: 10.1016/j.jmecsci.2005.03.003.

\section{Nomenclature}

\section{Symbols, Acronyms and Abbreviations}

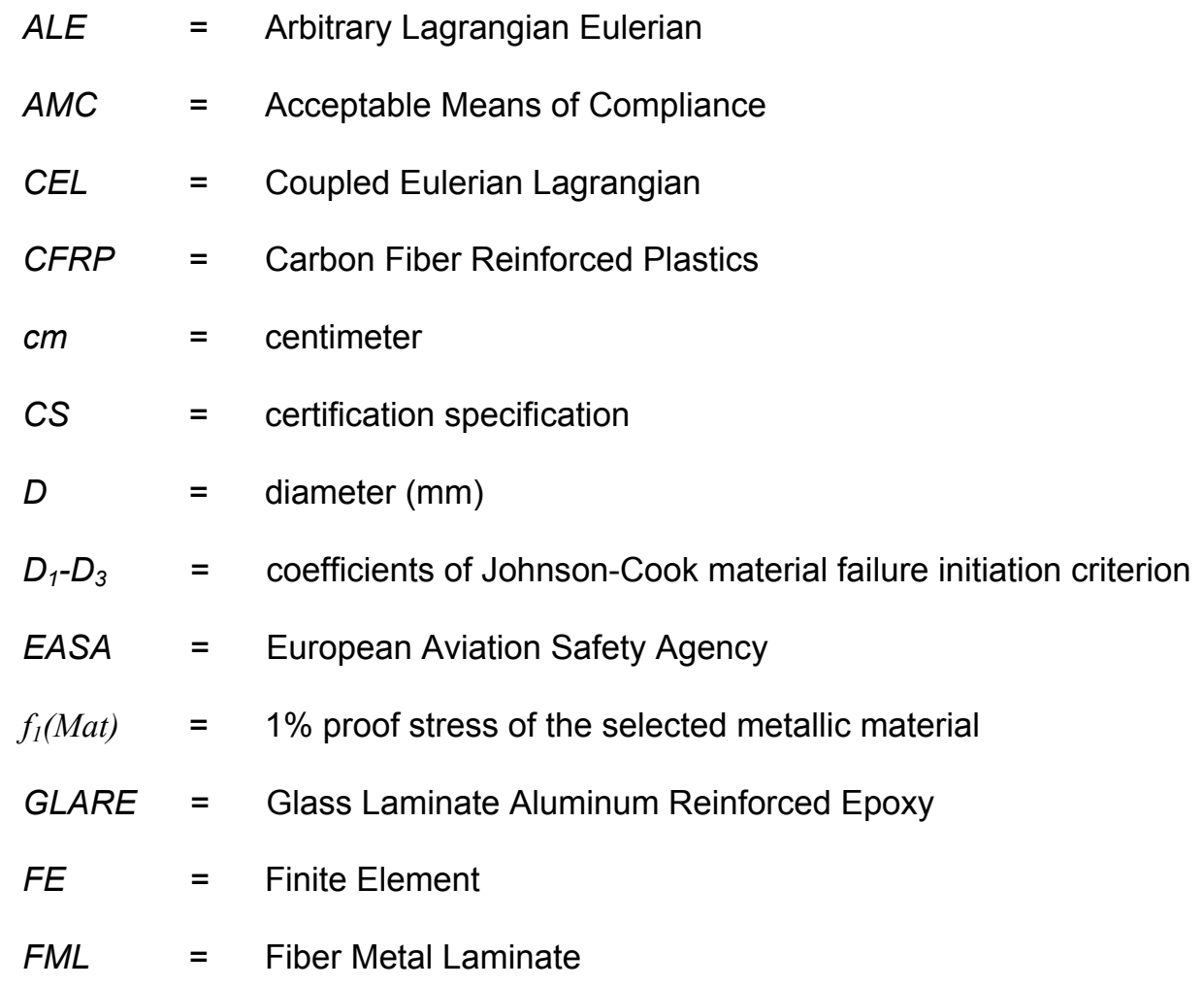


$F_{m}{ }^{t}=\quad$ unidirectional laminate failure index perpendicular to the fiber, under tensile loading

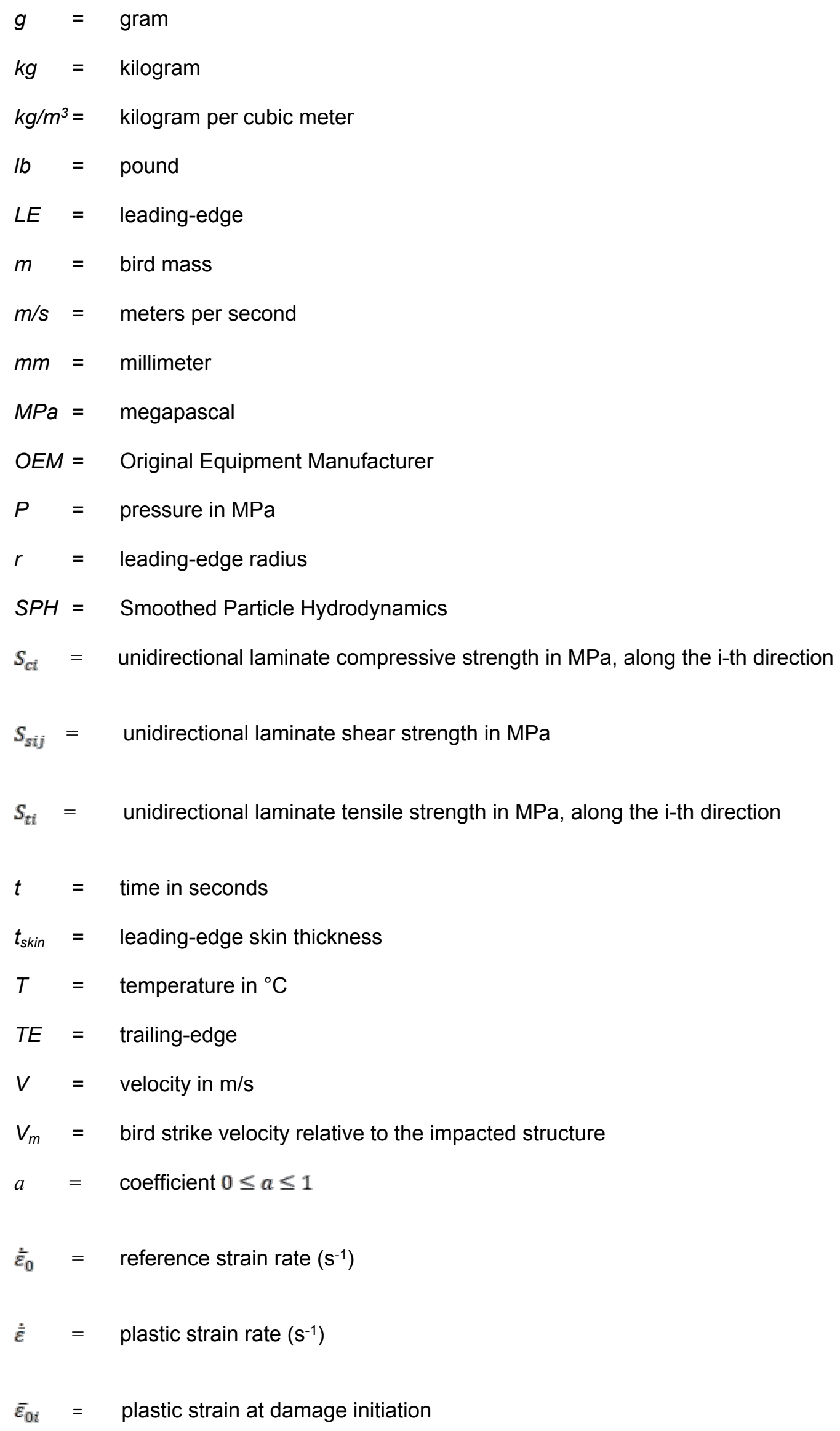


$\rho=$ density in $\mathrm{kg} / \mathrm{m}^{3}$

$\sigma \quad=\quad$ applied stresses in MPa

$\bar{\sigma}=$ von-Mises plastic equivalent stress (MPa)

\section{Subscripts}

$\begin{array}{lll}0 & = & \text { pre-impact state } \\ c & = & \text { compression } \\ f & = & \text { fiber } \\ m & = & \text { matrix } \\ \text { melt } & = & \text { melting } \\ N & = & \text { normalized } \\ s & = & \text { shear } \\ t & = & \text { tension } \\ t r & = & \text { transition }\end{array}$




\section{Bird Strike Virtual Testing for Preliminary Airframe Design}

Authors :

P. V. Perdikoulis

Aviation Consultant

Centre of Aeronautics, School of Aerospace, Transport and Manufacturing, Cranfield University, Cranfield, MK43 OAL, UK

petrosperdikoulis@gmail.com

I. K. Giannopoulos (corresponding author)

Senior Lecturer Aircraft Structures Design

Centre of Aeronautics, School of Aerospace, Transport and Manufacturing, Cranfield University, Cranfield, MK43 OAL, UK

i.giannopoulos@cranfield.ac.uk

$+447554345624$

E. E. Theotokoglou

Professor of Mechanics

Department of Mechanics, Laboratory of Testing and Materials, School of Applied Mathematical and Physical Sciences, National Technical University of Athens, GR-157 73, Greece

stathis@central.ntua.gr 
2021-02-25

\section{Bird strike virtual testing for preliminary airframe design}

Perdikoulis, Petros V.

Emerald

Perdikoulis PV, Giannopoulos IK, Theotokoglou EE. (2021) Bird strike virtual testing for preliminary airframe design. Aircraft Engineering and Aerospace Technology, Available online 25 February 2021

https://doi.org/10.1108/AEAT-09-2020-0212

Downloaded from Cranfield Library Services E-Repository 